\title{
Building Understanding of the Information Search Process Through Student Journal Writing
}

\author{
VIOLET H. HARADA \\ Department of Information and Computer Science, \\ University of Hawaii, \\ United States of America \\ vharada@hawaii.edu
}

\begin{abstract}
How is information transformed into knowledge? As library media specialists, our challenge is to help young people move from mechanics to meaning making in the information search process. This qualitative research study examined how journal writing reflected both the cognitive understandings and the affective expressions of students as they progressed through assigned research projects. The investigation, which was conducted at two elementary schools in Hawaii, also addressed how journal writing influenced modifications made in library instruction and how the journals affected librarians' one-on-one interaction with students. Research methodology employed, related studies examined, and findings discovered are described in this paper.
\end{abstract}

\section{INTRODUCTION}

Creating an information literate citizenry is essential in an age that is characterized by an ever-expanding universe of knowledge. The recent publication of standards in information literacy underscores the point that skills in processing information are as fundamentally important as reading and writing (American Association of School Librarians, 1998).

What are these skills and how should teachers and library media specialists facilitate their mastery? There are established models that define the skills comprising the information search process (e.g., Kuhlthau, 1993; Stripling \& Pitts, 1988; Eisenberg \& Berkowitz, 1990; Pappas \& Tepe, 1997). Broadly defined, the skills include 1) accessing information efficiently, 2) evaluating information critically, and 3) using information accurately and creatively.

To support learning these skills, educators are wrestling with teaching and learning paradigms, which challenge students to reflect on, interact with, and react to ideas presented to them (Hughes, Kooy, \& Kanevsky, 1997). A valued component in these models is having students write about their experiences.

Theorists and researchers have long argued for the use of language in an exploratory way so that students may make greater sense of their own learning (Vygotsky, 1962; Britton,1970; Halliday, 1975). Journal writing, in particular, is a strategy that allows students to reveal their reasoning and to demonstrate what they know. According to Anson 
and Beach (1995), such writing can improve thinking, which includes expressing emotional reactions; recording, summarizing and organizing perceptions; and exploring and extending thinking. Through this process, students sort their ideas and connect old learning to new knowledge.

Dialogue journals are written conversations in which the writer writes to a specific correspondent and receives response from that person (Wells, 1993). If the instructor is the respondent, he or she provides positive and constructive reactions to students' thoughts to lessen their anxieties about writing and to help them become more fluent journal writers.

The first comprehensive investigation of journal writing was conducted in 1979 in an elementary school classroom (Staton, Shuy \& Kreeft, 1982). This seminal work produced a valuable database for ethnographic research on the topic. In the ensuing decades, numerous studies have been published on the use of journal writing in various subject areas including social studies (Levitsky, 1991), mathematics (Gordon \& MacInnis, 1993), science (Johnstone, 1993), and the fine arts (Ameigh, 1992). Studies have also indicated the effectiveness of journals in English as a second language classrooms (Reyes, 1991).

More recently, Tallman (1998) reported on the positive influences of journal writing with high school students engaged in I-search projects. The students were able to describe successful research strategies as well as their frustrating experiences. Their reflections provided the teacher and library media specialist with ongoing clues to student progress. Journal writing also afforded an opportunity for the instructors to delve more deeply into students' written comments.

The present study attempted to extend this body of research with a field-based investigation focusing on the impact of journals in helping elementary grade students understand the information search process.

\section{RESEARCH METHODOLOGY}

\section{$\underline{\text { Research Questions }}$}

This qualitative research study examined students' use of journal writing as a means of cognitive understanding and affective expression during the information search process. Forty students, ages ten and eleven, at two elementary schools in Hawaii, comprised the population studied. Essential questions addressed in the study, which was conducted in the 1999-2000 school year, were:

- What understandings and problems do students express through their journals as they engage in a research assignment?

- What feelings do they express?

- How does journal writing influence instruction and the instructor's interaction with students?

\section{$\underline{\text { Population and Context }}$}

In school A, 23 fifth graders spent five weeks on a single project related to explorers of the New World and wrote journal entries at 11 points in the process. Although the teacher 
and library media specialist worked with students on a second assignment later in the fall semester, they were not able to have students complete their journal entries because of unforeseen scheduling difficulties.

In school B, 17 students in a combined grade classroom participated, including 7 fifth graders and 10 sixth graders. They spent a total of 11 weeks on two different research assignments dealing with ancient civilizations and their selection of historical heroes. Students wrote journal entries at 26 points in the process.

The classroom teacher and library media specialist collaborated on the units in both schools. As the primary instructors, the library media specialists introduced the following phases of the information search process:

- Presearch - exploring a general topic and conducting preliminary searches.

- Focus formulation and presentation planning-selecting a specific focus for the assignment, generating questions related to this focus, and planning for the final product.

- Collection and organization-locating and retrieving relevant information and taking notes using keywords.

- Presentation and evaluation-synthesizing information, creating the final product and presenting it, and evaluating both the product and the understanding of the information search process used.

In school A, 15 sessions were conducted for the single project. In school $\mathrm{B}$, the library media specialist coordinated a total of 20 sessions for the two projects. Both schools had flexible library scheduling, which enabled classes to use the library media center at least two or three times a week for 45 minutes to an hour. The teachers followed up with research-related tasks in their classrooms.

Both teams used specific journal prompts during the first assignments (e.g., Why is finding a focus important?). In school $\mathrm{B}$, the prompts were more open-ended during the second assignment (e.g., What did you do today? What problems did you discover?). Students in school A composed their journal entries on loose leaf paper while in school B, students used laptop computers and saved their entries on disks to share with the instructors.

\section{Methodology}

Exploratory and descriptive aspects of journal writing in relation to the information search process were investigated by identifying cognitive and affective levels of student responses and by documenting students' critical responses for the duration of the assignment.

The investigative team included the author (principal researcher), a teacher and a library media specialist at schools A and B, and two graduate students from the University of Hawaii's Library and Information Science Program. To achieve methodological triangulation, the team used several data gathering strategies including:

- Journal entries written by students. The entries served as the core data for textual narrative analysis. 
- Anecdotal records kept by the library media specialists. The logs provided critical insights into the instructors' own interpretation of specific incidents and their theoretical development in relation to this study.

- Fieldnotes recorded by a graduate student serving as a participant-observer at each school. These observations, which were recorded for all sessions conducted in the library media center, included reconstruction of dialogue, accounts of particular events, and depiction of activities.

- Interviews with the school teams conducted by the principal investigator. These were conducted on a monthly basis at each site over a period of six months. In addition, two joint-team meetings were also held.

Care was taken to ensure that none of the information collected would embarrass or harm the student participants. Parental consent was required for all children involved in the study.

The principal investigator and the graduate students coded the journal entries using a sentence cluster as the unit of analysis. A cluster consisted of two to ten contiguous sentences within a journal entry that reflected a cognitive response to a specific phase (e.g., presearch activities provide an overview of a general topic) or that mirrored a predominant affective response (e.g., frustration resulting from inability to find relevant information).

The sentence clusters were arranged by journal entry dates and then categorized as cognitive or affective responses. If a response contained elements of both, it was assigned to both categories.

To determine cognitive response levels, the team adapted a coding scheme used by Staton (1988) in her analyses of journal writing. The four levels of cognition (C) were:

- (C1) Unrelated information-writer is unable to provide information related to a concept or procedure.

- (C2) Disjointed recall-writer is able to regurgitate or recall bits of information relevant to a concept or procedure.

- (C3) Re-statement of concept with limited supporting comments-writer is able to re-state a concept or procedure and to provide one or two relevant details.

- (C4) Elaborated statement of concept-writer is able to re-state a concept or procedure and to provide commentary that supports it with coherent detail, links it with previous experiences, relates it to a larger issue or context, and/or extends it through judgmental and evaluative comments.

Affective (A) responses were coded using the following stages identified in Kuhlthau's research (1993) on students' emotional expressions throughout the information search process:

- (A1) Optimism, usually during the presearch phase.

- (A2) Doubt, frustration, usually during the focus formulation and initial information gathering phases. 
- (A3) Confidence, usually during the latter stage of information collection and during the presentation preparation phase.

- (A4) Satisfaction or dissatisfaction, usually following a student's completion of work.

Each journal entry was coded independently by the principal investigator and one of the graduate students. Using a reliability measurement suggested by Fraenkel and Wallen (2000), the team estimated the percentage of agreement of their coding by tabulating the number of instances of agreement and disagreement, dividing the number of instances of agreement by the total number of instances, and multiplying that quotient by 100 . There was a $91.3 \%$ agreement for school A coding and an $87.2 \%$ agreement for school B. All disagreements were resolved by discussion among the three coders. Finally, the coded entries were tabulated and percentages derived to allow for reporting of aggregate results.

\section{FINDINGS/RESULTS}

What understandings and problems do students express through their journals as they engage in a research assignment?

$\underline{\text { School A }}$

In school A, students wrote journal entries about twice weekly for a research assignment that lasted five weeks. Table 1 summarizes the cognitive levels of their entries.

\section{Table 1}

School A: Coding of Cognitive Journal Responses for Cycle 1

\begin{tabular}{|c|c|c|c|c|}
\hline \multirow{2}{*}{ Response } & Presearch & Focus & Collect/Organize & Present/Assess \\
\hline & $(\mathrm{N}=32)$ & $(\mathrm{N}=19)$ & $(\mathrm{N}=158)$ & $(N=44)$ \\
\hline $\begin{array}{l}\text { (C1) Unrelated } \\
\text { information }\end{array}$ & $17(53 \%)$ & $9(47 \%)$ & $32(20 \%)$ & $9(21 \%)$ \\
\hline $\begin{array}{l}(\mathrm{C} 2) \text { Disjointed } \\
\text { recall }\end{array}$ & $10(31 \%)$ & $8(42 \%)$ & $50(32 \%)$ & $19(43 \%)$ \\
\hline $\begin{array}{l}\text { (C3) Restated, } \\
\text { limited support }\end{array}$ & $4(13 \%)$ & $2(11 \%)$ & $61(39 \%)$ & $11(25 \%)$ \\
\hline $\begin{array}{l}\text { (C4) Restated, } \\
\text { elaborated }\end{array}$ & $1(3 \%)$ & 0 & $15(9 \%)$ & $5(11 \%)$ \\
\hline
\end{tabular}

Presearch. During this phase, students were asked to explain what they knew about the "Age of Exploration" in their journals. To introduce the general notion of exploration, the teacher had previously queried students about their own experiences related to "exploring in your backyards." In addition, students had viewed a video on exploration and colonization of the New World. 
For over half $(53 \%)$ of the students these initiating activities appeared to confuse rather than clarify the unit focus on exploration of the New World. Many of their responses reflected an inaccurate identification of the time period covered and included disjointed comments. A typical entry:

In the 1800 s hundreds of people began to explore more and more from land to water to space, to this day people are still exploring this way. I explore in my backyard sometimes. I find bugs or new plants. The age changed the world by finding new places like the Polynesians explored Hawaii. Marco Polo explored China. Columbus found America. I found a new tree in my backyard.

Only $16 \%$ articulated that this was a period when sea-faring countries of Europe sought to expand their influence and the implications of their exploration. One student wrote:

The age was when explorers from Europe searched for new land. Some explorers went for food or riches or just land to claim for their country. The age changed the world because no one would have found the country we live in or spices, silk, or some exotic foods. We would have never known about some geographical features about the earth. Why, we may still be thinking the world is flat if it weren't for explorers.

Focus formulation and presentation planning. Students were asked to explain why it was important to have a research focus. Nearly half $(47 \%)$ of the students were uncertain about the purpose for formulating a focus. One student volunteered:

I don't really know what it means but maybe it means to have a focus so you don't have to look in the books back and forth. Maybe it means to look for only one thing at a time.

Two students reflected some understanding of the concept. One of them pointed out:

It's important to have a topic focus because you can't research the whole topic. It is too big. But if you take only a little piece you will at least be able to do a good job of finding information and reporting it.

Collection/organization. The bulk of the entries focused on students' experiences related to locating resources and taking notes.

When asked to describe how to take "good notes," over $60 \%$ of the students could identify at least one of the following points: use a variety of sources, search for keywords in texts, find accurate and relevant information, and take notes in one's own words. Another $26 \%$ could elaborate on many of these aspects. An example:

In order to have good notes you have to use keywords. For example, Columbus brought potatoes, tomatoes and cacao. The keyword would be foods. I would underline or highlight what foods he brought and why. Another criteria [sic] is to be accurate. You have to have information you found in books, encyclopedias, print and electronic, and magazines. Not things you made up. Also, your notes have to answer your questions. Like if you have a question on where Columbus explored, you wouldn't take notes on his birthplace. Another thing is to skim, scan, and read before you take notes. Then when you find your information, you write it down in your own words. 
Students were also queried on to what they felt were the "most useful resources" thus far in their searches. The teacher and library media specialist predicted that the majority would single out web sites. They were surprised when all but three students identified either the print or electronic versions of the encyclopedia as the most reliable and useful source. As one student noted:

The print and electronic encyclopedias were best because they gave us information we needed to answer each of the questions. Also the information was in paragraphs with good headings so it was easier to find the answers. Also they gave you accurate info and complete info.

Final presentation and evaluation. Students responded to prompts that asked them to assess their strengths and weaknesses as researchers and to comment on the value of writing in their journals throughout this project.

All students indicated that they had improved in some facet of information searching. Over half $(52 \%)$ of them stated that they had strengthened their skills in locating and retrieving information. They were familiar with a wider range of resources ("I always used the Internet before, now I also use encyclopedias and books"). They were also more methodical in their searches ("I can find stuff using the OPAC. Before I went right to the shelves"). Another 26\% stated that they were better note takers ("I don't copy so much").

Students were also queried about areas where they might improve their skills. Over $20 \%$ of them admitted that note taking was difficult. As one student explained, "It is hard to highlight keywords and then make your own sentences." Other problem areas identified by at least two students included locating information on the Internet and in print and electronic encyclopedias, and retrieving books useful for their research.

When asked about the benefits of journal writing, almost a third of the students misinterpreted the prompt and commented instead on the logistics of journal management. For example, one girl wrote, "I don't think it was a good idea because some people could lose the journal."

A majority of the students $(70 \%)$, however, indicated that the journal was a concrete record of what they had done and provided a tool for assessing their future performance. An example:

Later on after your research, you can look back and see what you did. You can see what you could do better than before. You can also see what you thought.

One student specifically commented on journal writing as a tool for ongoing assessment and assistance:

I think that doing a dialogue journal was a very good idea because we can reflect on what we were doing. We can also tell you what we think and our ideas on the explorers. We can tell you what problems we are having so you can help us. I know from experience that a lot of questions can be answered through the journal.

\section{$\underline{\text { School B }}$}

In school B, students kept journal entries at least twice weekly during both research 
assignments. Table 2 summarizes the cognitive levels of their journal entries.

\section{Table 2}

School B: Coding of Cognitive Journal Responses for Cycles 1 and 2

\begin{tabular}{|c|c|c|c|c|}
\hline & Presearch & Focus & Collect/Organize & Present/Assess \\
\hline Response level & $\begin{array}{l}(\text { Cycle } 1=71) \\
(\text { Cycle } 2=16)\end{array}$ & $\begin{array}{l}(\text { Cycle } 1=18) \\
(\text { Cycle 2 }=34)\end{array}$ & $\begin{array}{l}(\text { Cycle } 1=15) \\
(\text { Cycle } 2=12)\end{array}$ & $\begin{array}{l}(\text { Cycle } 1=58) \\
(\text { Cycle } 2=88)\end{array}$ \\
\hline $\begin{array}{l}\text { (C1) Unrelated } \\
\text { information }\end{array}$ & $\begin{array}{r}28(39 \%) \\
1 \quad(6 \%)\end{array}$ & $\begin{array}{l}2(11 \%) \\
5(15 \%)\end{array}$ & $\begin{array}{r}8(53 \%) \\
0\end{array}$ & $\begin{array}{r}14(24 \%) \\
3(3 \%)\end{array}$ \\
\hline $\begin{array}{l}(\mathrm{C} 2) \text { Disjointed } \\
\text { recall }\end{array}$ & $\begin{array}{r}16(23 \%) \\
6(38 \%)\end{array}$ & $\begin{array}{l}11(61 \%) \\
16(47 \%)\end{array}$ & $\begin{array}{l}2(13 \%) \\
8(67 \%)\end{array}$ & $\begin{array}{l}11(19 \%) \\
15(17 \%)\end{array}$ \\
\hline $\begin{array}{l}\text { (C3) Restated, } \\
\text { limited support }\end{array}$ & $\begin{array}{r}21(30 \%) \\
5(31 \%)\end{array}$ & $\begin{array}{r}4(22 \%) \\
12(35 \%)\end{array}$ & $\begin{array}{l}4(27 \%) \\
3(25 \%)\end{array}$ & $\begin{array}{l}32(55 \%) \\
33(38 \%)\end{array}$ \\
\hline $\begin{array}{l}\text { (C4) Restated, } \\
\text { elaborated }\end{array}$ & $\begin{array}{l}6(8 \%) \\
4(25 \%)\end{array}$ & $\begin{array}{ll}1 & (6 \%) \\
1 & (3 \%)\end{array}$ & $\begin{array}{ll}1 & (7 \%) \\
1 & (8 \%)\end{array}$ & $\begin{array}{r}1(2 \%) \\
37(42 \%)\end{array}$ \\
\hline
\end{tabular}

Presearch. Students were asked to explain the value of exploring a broad topic and to describe what they did in the presearch phase. In the first research assignment, over twothirds of the students could not articulate the purpose for exploring a general topic. They either vaguely defined it as finding information ("It helps me because I can get information from a book") or stated that it was extraneous to the process itself ("When do we start the REAL project?").

By the end of the second research assignment, however, $56 \%$ of the responses indicated that the presearch phase was important in helping students gain a broader overview of a general topic and that this helped them to select a more specific area for research. One student, who initially wrote that exploring a topic helped him "find the correct answer," presented the following insights in the second cycle:

In presearch, you choose a broad topic to research that has a lot of smaller topics in it. You look in sources to find information on the topic, branch out, use more than books-use the Internet, encyclopedia, magazines, etc. It helps you narrow down choices. With more information you can decide which will be easier to find or which one sounds more interesting.

Focus formulation and presentation planning. During the first assignment, students were asked to describe how they selected their research focuses. Nearly $90 \%$ of the students stated that they based their choices on personal interests. To a lesser extent, they mentioned the influence of prior reading, the availability of resources, and discussions with peers and with family members. One boy stated:

I was drawn to the Incas because there was a lot of interesting information about them in the encyclopedias and Internet. Unlike the Aztecs, the Incas don't do gory sacrifices. Yesterday my dad said that scientists found some type of new pyramid that the Incas made. 
In the second assignment, the teacher and library media specialist asked students to describe how they planned to work on their presentations. The majority $(62 \%)$ was either confused by the prompt or supplied superficial descriptions of their activities. A typical response:

Today I went to the library. We set up our laptop. Then Ms. S [library media specialist] told us what we had to do. I got right to bissiness [sic]. Then we had to go.

A third of the students furnished bits of information on the technical requirements of the presentation and identified some of the initial steps they planned to take. A student, who was planning an oral project, wrote:

We went to the library to talk about the types of presentations we might do. Everyone had lots of questions. We might do stuff like talk shows or TV shows. I want to do something with PowerPoint. I am doing it on Abraham Lincoln. I have to take notes and the presentation needs to be at least $3 \mathrm{~min}$. long. I need to meet with Ms. S [library media specialist] to lay out my presentation. Also I need to do a storyboard.

Collection/organization. During the first assignment, over half of the students could not describe the note taking process they had been taught, i.e., selecting keywords or simple phrases instead of complete sentences. For example, one girl said, "We take notes by getting a sheet of paper to write down our area we are doing. "

At the end of the second assignment, all students could restate major steps in the note taking process and a third of were able to elaborate on the process. One student, who was initially nebulous about the note taking process, provided the following explanation during her second project:

\begin{abstract}
You skim and scan through your resources. Take your time while doing this step. While skimming you tag important sections then it will be easier to go back to that page and find important information. Take notes in your own words. You can write short answers (keywords) that are no more than three words. You do the keywords first and after you are done you write the long answers that are sentences you make using the words you wrote down.
\end{abstract}

Presentation and evaluation. Students were invited to reflect on what they had done at the end of each research cycle and to offer advice to new researchers. At the end of the first assignment, $24 \%$ of the responses were brief and inexplicit ("Tell them to take the same steps as I did in this project"). By the end of the second assignment, over $90 \%$ were able to describe major aspects of the process in their own words. Marked differences between students' first and second entries (i.e., from $\mathrm{C} 1$ to $\mathrm{C} 3$ levels and from $\mathrm{C} 2$ to $\mathrm{C} 4$ levels) were noted for at least half of the students For example, one girl wrote the following after the first assignment: "You search, then focus, collect information and present it." At the end of the second assignment she explained:

You choose a broad topic. You might ask your teacher what you should write your report on, or what she requires you to do. To get a general picture, look through different resources. See if the resources are understandable. Choose the topic that you think most people wouldn't pick because you could teach others something they might not have known. Make who, what, when, where, why and how questions. 
Find resources, scan through them. Use as many different resources as possible. Take notes by writing key words. Don't copy your answers out of a book because the teacher knows what kind of work you do. Now you are ready to put it into paragraphs. Put the info together so that it makes sense. Use correct grammar and check over your work. Finally you show others what you learned. Then you have to assess your work. Be truthful. If you grade untruthfully, you will only be fooling yourself. In conclusion, doing a project is very time consuming and it takes patience. Each time you do a project it should get better and better. Never TRY to do your best; just $\mathrm{DO}$ your best. assignments?

What feelings do students express through their journals as they work on their

Affective entries were not collected in any consistent fashion at school A, largely because the journal prompts focused on cognitive understandings (e.g., What are criteria for good notes? How did you collect information on your explorers?). On the other hand, many journal prompts in school B invited affective responses (e.g., How do you feel about the research process so far?). Hence data on this research question are reported from the latter school only.

The majority of the affective responses followed a pattern of emotional peaks and valleys reported in Kuhlthau's earlier studies (1993). The exception was in the focus formulation phase where students were divided between feelings of optimism and frustration. Table 3 summarizes their responses for both research assignments.

Table 3

School B: Coding of Affective Journal Responses for Cycles 1 and 2

\begin{tabular}{|c|c|c|c|c|}
\hline \multirow[b]{2}{*}{ Response level } & \multirow{2}{*}{$\begin{array}{c}\text { Presearch } \\
\text { (Cycle } 1=18) \\
\text { (Cycle } 2=15) \\
\end{array}$} & Focus & \multirow{2}{*}{$\begin{array}{l}\text { Collect/Organize } \\
\text { (Cycle } 1=13) \\
\text { (Cycle } 2=13)\end{array}$} & \multirow{2}{*}{$\begin{array}{l}\text { Present/Assess } \\
(\text { Cycle } 1=16) \\
\text { (Cycle } 2=20\end{array}$} \\
\hline & & $\begin{array}{l}(\text { Cycle } 1=27) \\
\text { (Cycle 2 }=38) \\
\end{array}$ & & \\
\hline (A1) Optimism & $\begin{array}{l}13(72 \%) \\
13(87 \%)\end{array}$ & $\begin{array}{l}17(63 \%) \\
17(45 \%)\end{array}$ & $\begin{array}{l}0 \\
0\end{array}$ & $\begin{array}{l}0 \\
0\end{array}$ \\
\hline (A2) Doubt & $\begin{array}{l}5(28 \%) \\
2(13 \%)\end{array}$ & $\begin{array}{r}8(30 \%) \\
21(55 \%)\end{array}$ & $\begin{array}{l}1(8 \%) \\
4(31 \%)\end{array}$ & $\begin{array}{l}0 \\
0\end{array}$ \\
\hline (A3) Confidence & $\begin{array}{l}0 \\
0\end{array}$ & $\begin{array}{ll}2 & (7 \%) \\
0\end{array}$ & $\begin{array}{r}12(92 \%) \\
9(69 \%)\end{array}$ & $\begin{array}{l}0 \\
0\end{array}$ \\
\hline $\begin{array}{l}\text { (A4) } \\
\text { Satisfaction } \\
\text { Dissatisfaction }\end{array}$ & $\begin{array}{l}0 \\
0\end{array}$ & $\begin{array}{l}0 \\
0\end{array}$ & $\begin{array}{l}0 \\
0\end{array}$ & $\begin{array}{c}15(94 \%) \\
1(6 \%)\end{array}$ \\
\hline & $\begin{array}{l}0 \\
0\end{array}$ & $\begin{array}{l}0 \\
0\end{array}$ & $\begin{array}{l}0 \\
0\end{array}$ & $\begin{array}{r}13(65 \%) \\
7(35 \%)\end{array}$ \\
\hline
\end{tabular}


Presearch. During this stage, $72 \%$ (first cycle) and $87 \%$ (second cycle) of the entries reflected optimism and enthusiasm about the work ahead. Students cited the excitement of finding new information ("I like research because you get to learn about things you have never known before"), the novelty of a new way of learning ("This is a better way to learn because you have hands on activities and you get to look up stuff"), and the value of research assignments to future academic success ("It will help me in middle school and college").

Focus formulation and presentation planning. Responses were divided between continuing optimism $(65 \%$ and $44 \%)$ and growing doubt and frustration $(31 \%$ and $54 \%)$ regarding the assignments. Students, who were positive about their progress, indicated they enjoyed the challenge of selecting their own research focus. One girl stated, "This is much better than looking for stuff in our textbooks." Another felt empowered: "I like selecting my own topic because it makes me feel like I'm in charge and that I can choose what I want to do and what I don't want to do."

On the other hand, students, who were unsure of task expectations and befuddled over the search process itself, expressed concern. As one student wrote: "I feel misplaced because I am not really sure of what I am supposed to do. I kind of feel like I am doing something wrong."

Collection/organization. During the first cycle, $92 \%$ of the students expressed confidence in their note taking skills although, as earlier reported, many of them could not describe the process itself. The teacher and library media specialist discussed this discrepancy between students' lack of cognitive understanding of the note taking process and their self-perceptions of efficacy. Through reading the log entries, the instructors realized that students might be able to mechanically perform the task without necessarily internalizing the process.

During the second cycle, over two-thirds of the students expressed confidence in their ability to locate and retrieve information from different sources. The remaining third voiced frustration, mainly targeting problems with the lab computers and with Internet access ("Oh no! Internet Explorer is going so slow. This is going to take forever").

Presentation and evaluation. The majority of the students were satisfied with their products for both assignments (94\% and 65\%). One girl elatedly wrote:

YES! I'm done!! I can't believe it! I think that my trading cards turned out really well. I mean when your mom says that you can make money off of making trading cards you can't be doing too bad!

Those who were dissatisfied ( $6 \%$ and $35 \%$ ) admitted that they needed to invest more time on their projects ("Next time, I will rehearse a lot more because our presentation wasn't as good as I imagined it would be"). Several students also divulged that their team members needed to work more closely together. This sentiment was reflected in the following entry:

Rehearsing together would help a lot. We must get people to come and rehearse because every time people were either busy, wanted to play, or weren't there. 
The teacher and library media specialist discussed the increase in student dissatisfaction with the products required in the second assignment and attributed this to their own lack of closer monitoring. The library media specialist indicated in her log:

There is no doubt that the trading cards look good, from a distance. When we examine them closely, a majority of them leave much to be desired. I think we let the students work too independently. What we needed to do was work with them more closely as they gathered their information, then help them with synthesizing the information. We needed to give them more exemplars as well as poor examples. students?

How does journal writing influence instruction and the instructor's interaction with

Impact on instruction. The teams in both schools concurred that reading the students' journals helped them develop deeper insights into the complexity of the research process. In interviews with the teams, they indicated becoming "more acutely aware" of the numerous sub-skills embedded in each step of the research process. Not only were the students overwhelmed at points, so were the instructors. In an anecdotal $\log$, the library media specialist in school B admitted:

I guess that in the past, I hadn't been so conscious of the research process and I would just do those parts that the teachers asked me to do, e.g., get resources, take notes, cite sources. But because I'm working on all phases of the process this time, I'm really feeling overwhelmed.

They also stated that in a whole group instructional setting, it was impossible to note the individual progress of each child. However, the journals provided them with critical snapshots of each student, including the quiet or shy child who might be overlooked in a busy classroom. For example, the library media specialist in school A noted:

$\mathrm{J}$. is a quiet student who can easily go unnoticed in the class. His journal revealed a high level of frustration. He asked where he could find more information on his topic. I suggested a few specific resources, mostly books. I will try to watch him to be sure that he doesn't get discouraged.

The journals provided the instructors with rich, continual feedback on the effectiveness of their intervention strategies. Although both library media specialists felt they had done an effective job of introducing skills at each point of the search process, the confusion and lack of understanding reflected in the journals often surprised them. Using the students' comments to retool their instruction, the teams identified the following as critical pedagogical insights:

- Explicit strategy instruction must include extensive modeling ("I thought one example was adequate but I will need to provide more of them") and discussion of thinking ("Students need to know why I am doing something and what I am thinking as I do it if I want them to model this behavior themselves").

- Students should learn and practice only one new strategy at a time ("The problem was that I had presented the process of information collection and the criteria for note taking in one quick session. I thought they could handle this. I should have separated the concepts into at least two sessions"). 
- Reflection is a learned skill that requires extended practice and feedback. One of the teachers interviewed said, "Many of my students had never written journals before. I feel they needed more encouragement to write as well as feedback from us." The teams also felt they should have provided more time after the sessions for journal writing. Often, students had less than five minutes to scribble their entries. As part of a focus group discussion in school B, students themselves indicated they wanted more time for the journal entries.

Impact on interaction. In addition to the implications of journal writing on instructional intervention, the dialogue journals nurtured a communal sense of learning among students and instructors. Both teams noted a growing collegial atmosphere, which promoted a freer exchange of questions and opinions between instructors and students. For example, when the library media specialist in school A made a point in class, students readily offered additional perspectives. She noted in her log:

While I was instructing today, several students said, "But my resource said...." and offered additional information. In other words, they were going beyond just copying what was offered on my overhead transparency. I think there is a definite connection between students writing freely in their journals and asking questions.

The journals also seemed to spark increased interaction among the students themselves. The library media specialist in school B observed that the extent and depth of the exchanges were greater in this class than in a comparable class that was working on a similar research assignment:

The students are dialoging among themselves as they read. I am also pleased with the interaction that is occurring across the teams at the different tables. There's a lot of discussion about the meanings of words, questions they have as they take notes, and problems they need to solve as they prepare their presentations. In my other class, there is less discussion within teams and none across teams.

Possible adjustment to journal writing. While the teams were enthusiastic over the results, they acknowledged the labor-intensive nature of dialogue journals. An alternative they hoped to explore was the incorporation of peer as well as instructor responses in the process. Pairs of students could exchange entries and begin carrying on a conversation in writing, focusing on the subject matter of the class. An advantage to this latter strategy is that students may be more likely to share feelings, doubts and concerns with peers than with adults (Anson \& Beach, 1995).

\section{CONCLUSIONS}

As Moore (1995) discovered in her research on information searching with New Zealand elementary school students, the thinking underlying information problem solving is tremendously complex. Students involved in the Hawaii study were primarily novice searchers. They initially possessed bits and pieces of conceptual knowledge about the information search process; however, through the process of journal writing, the majority were able to demonstrate increased cognitive and metacognitive understanding of the information search process. To varying degrees, they were able to assess what they viewed as strengths and weaknesses that affected their learning. Nonetheless, it should be noted that 
the ability to verbalize their own mental processes was a formidable challenge for most of the students; and that they must have sustained opportunities to monitor their own comprehension.

Personal feelings and emotions were readily explored and expressed as trusting relationships were built in the journal communication. Students openly shared their difficulties and frustrations because the journal was not seen as an evaluative tool. They felt safe to take risks and to experiment with form, style, and voice.

For the instructors, journal writing revealed variations in students' perceptions of the information search process that were not readily apparent during their whole class interactions. Through their journals, all students were simultaneously engaged in translating and personalizing knowledge.

Rather than relying only on gut intuitions about students' needs and performances, both instructional teams indicated that studying student journal responses supplied them with critical data on which to base informed judgments. The journals afforded them valuable ongoing assessment of actual student comprehension of the information search process and helped them refine their intervention strategies.

In short, the study substantiated for these teams the importance of promoting understanding of the information search process itself rather than concentration on the product alone. While these findings were not generalizable since the contexts were very specific; the researchers hope that the insights presented might encourage other school teams to replicate aspects of this study in their own settings.

\section{ACKNOWLEDGEMENTS}

The author acknowledges the following individuals who were members of the research team: Claire Sato, library media specialist, Shafter Elementary; Eileen Suda, teacher, Shafter Elementary; Joan Yoshina, library media specialist, Mililani Mauka Elementary; Teri Ushijima, teacher, Mililani Mauka Elementary; Mary Heckman and Brenda Booker, graduate students, University of Hawaii, Library and Information Science Program.

\section{REFERENCES}

Ameigh, T. (1992). Learn the language of music through journals. Music Educators Journal $79,30-32$.

American Association of School Librarians/Association for Educational Communications \& Technology (1998). Information power: Building partnerships for learning. Chicago: American Library Association.

Anson, C. M., \& B., Richard. (1995). Journals in the classroom: Writing to learn. Norwood, MA: Christopher-Gordon.

Britton, J. (1970). Language and learning. Suffolk, UK: The Chaucer Press.

Eisenberg, M. B., \& Berkowitz, R. E. (1990). Information problem-solving: The big six skills approach to library and information skills. Norwood, NJ: Ablex.

Fraenkel, J. R., \& Wallen, N. E. (2000). How to design and evaluate research in education $4^{\text {th }}$ ed. Boston: McGraw Hill. 
Gordon, C. J., \& MacInnis, D. (1993). Using journals as a window on students thinking in mathematics. Language Arts 70,37-43.

Halliday, M.A.K. (1975). Language as a social semiotic. Baltimore, MD: University Park Press.

Hughes, H. W., Kooy, M., \& Kanesvsky, L. (1997). Dialogic reflection and journaling. The Clearing House, 670, 187-190.

Johnstone, A. (1993). Uses for journal-keeping: An ethnography of writing in a university science class. Norwood, NJ: Ablex.

Kuhlthau, C. C. (1993). Seeking meaning: A process approach to library and information services. Norwood, NJ: Ablex.

Levitsky, R. (1991). Journal writing in the social studies. Social Studies Review 31, 50-54.

Moore, P. (1995). Information problem solving: A wider view of library skills. Contemporary Educational Psychology 20, 1-31.

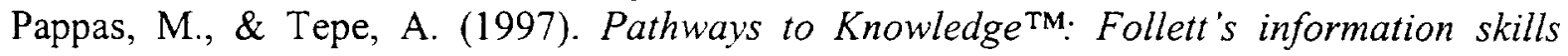
model. McHenry, IL: Follett Software.

Reyes, M. L. (1991). A process approach to literacy using dialogue journals and literature logs with second language learners. Research in the Teaching of English 25, 291-313.

Staton, J. (1988). Dialogue journal communication: Classroom, linguistic, social, and cognitive views. Norwood, NJ: Ablex.

Staton, J., Shuy, R. W., \& Kreeft, J. Y. (1982). Analysis of dialogue journal writing as a communicative event. Final Report; Volumes 1 and 2. Center for Applied Linguistics, Washington, DC: (ERIC Document Reproduction Service. Nos. Ed 214196 and 214 197).

Stripling, B., \& Pitts, J. M. (1988). Brainstorms and blueprints: Teaching library research as a thinking process. Englewood, $\mathrm{CO}$ : Libraries Unlimited.

Tallman, J. (1998). I-search: An inquiry-based, student-centered, research and writing process. Knowledge Quest 27 (1), 20-27.

Vygotsky, L. S. (1962). Thought and language. Cambridge: M.I.T. Press.

Wells, C. W. (1993). The dialogue journal: Connection to critical thinking. Teaching Sociology 21, 182-186. 